\title{
MEASUREMENT OF ULTRAFINE AEROSOL SIZE DISTRIBUTIONS BY A MULTI-CHANNEL DIFFUSION SEPARATOR-CPC SYSTEM
}

\author{
Ph. FELDPAUSCH, A. PETZOLD, L. FRITZSCHE, A. MINIKIN \\ Institut für Physik der Atmosphäre, Deutsches Zentrum für Luft- und Raumfahrt Oberpfaffenhofen, \\ 82234 Wessling, Germany
}

Keywords: DIFFUSION SEPARATOR, DIFFUSION BATTERY, NANOPARTICLES.

\section{INTRODUCTION}

So far, on-line measurements of aerosol size distributions in the sub- $\mu \mathrm{m}$ regime were accomplished by a Condensation Particle Size Analyzer (CPSA) for the size range $d_{P}<20 \mathrm{~nm}$ and a conventional DMA for the size range $10-1000 \mathrm{~nm}$. The CPSA is a four channel instrument based on CPC-technique. It provides information in the size range from 3 to $20 \mathrm{~nm}$ with a time resolution in the order of seconds (Schröder 2000, Stein et al. 2001). Because of the DMA measurement principle its time resolution is reduced compared to the CPSA. Since aerosol measurements of combustion processes and airborne measurements of atmospheric aerosols require high time resolution, a new instrument combination of diffusion separators (DS) coupled to CPCs was developed in order to cover the size range from $3 \mathrm{~nm}$ to approx. $120 \mathrm{~nm}$ with a fast-responding and simple instrument.

\section{METHODS}

In a DS, sample air is drawn through a series of very fine meshed stainless steel screens, which are chemically inert. Due to processes of diffusion, interception, and impaction, particles are deposited to the screen wires. So the DS is principally similar to the well known diffusion battery (DB). The probability of particle traverse through a DS is described by the so called penetration $P$. Since the loss processes are particle size dependent the penetration $P$ depends on the particle diameter $d_{p}$. After the sample air passes the DS the remaining particles are counted by a CPC. Consequently the DS-CPC system is particle size sensitive. To obtain a particle size distribution by calculation the penetration of the DS, the transfer function of the $\mathrm{CPC}$, and the counted number density must be certainly known.

\section{RESULTS AND DISCUSSION}

As known from theory $P$ depends on the number of screens $n_{S}$, the volumetric flowrate $q$, and the absolut pressure $p$. So the dependence of $P\left(d_{p}\right)$ on these parameters was investigated. Table 1 shows all parameter configurations for calibration experiments. For calibration monodisperse carbonaceous aerosol was generated and its size controlled by a DMA. The left part of Figure 1 shows one set of calibration experiments (data points) compared to the theory (lines). The comparison between experimental results and established theory (Hinds, 1999) shows excellent agreement within the limits of the calculated errors.

Table 1. Parameter configurations of calibration experiments.

\begin{tabular}{ccc}
\hline number of screens & volumetric flowrate & absolute pressure \\
$n_{S}$ & $q, 1 \mathrm{pm}$ & $p, \mathrm{hPa}$ \\
\hline 3 & 0.99 & $200,400,600,800,950$ \\
3 & 1.51 & 955 \\
8 & $0.99,1.51,1.61,1.89$ & 955 \\
10 & 1.51 & $200,400,600,800,950$ \\
17 & 1.46 & $200,400,600,800,950$ \\
17 & 0.99 & 955 \\
\hline
\end{tabular}



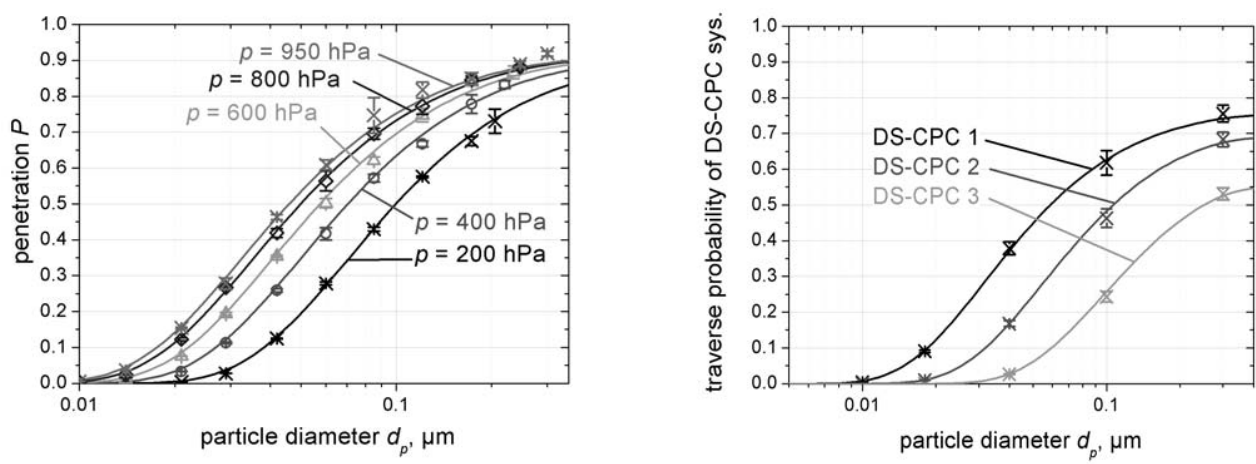

Figure 1. left: Comparison between the penetration values acquired in calibration experiments (data points with error bars) and theoretical prediction (lines) for a set of parameters: $n_{S}=3, q=0.99 \mathrm{lpm}, p=$ 950, 800, 600, 400, $200 \mathrm{hPa}$. right: Comparison between experimental penetration values (data points with error bars) and theory (lines) for a set of three DS-CPC systems.

The validity of the DS penetration theory originally derived for standard conditions is empirically expanded into the pressure range of 955 down to $200 \mathrm{hPa}$. Moreover the factor $B$ in the equation for the single fiber efficiency of diffusion $\left(E_{D}=B P e^{-2 / 3}\right)$ used to calculate the penetration was found to be constant $(B=2.70 \pm 0.23)$ within the investigated parameter ranges. This result is in agreement with those of Kirsch (Kirsch et al., 1968). However the experiments of Kirsch et al. were conducted only for standard pressure conditions.

A three channel DS-CPC system was successfully tested with monodisperse carbonaceous aerosol. The right part of Figure 1 shows the theoretically expected transfer functions (lines) compared to the experimental determinated values for the indicated particle sizes (data points with error bars). A seven channel instrumentation consisting of the existing four channel CPSA and the three channel DS-CPC system was successfully tested under operational conditions. This seven channel instrument was also successfully used to characterize a synthetically generated polydisperse carbonaceous aerosol in the size range from about 3 to $120 \mathrm{~nm}$. As a further successful application under real conditions aerosols were measured in the exhaust gas of a single-cylinder test bed engine.

Since the tested screens ${ }^{1}$ are quite similar to the screens used in the TSI Particle Size Selector (Model 376060) the presented results can also be assigned to this system.

${ }^{1}$ Technical specifications of tested screens: solidity fraction $\alpha=0.368 \pm 0.021$, aperture size $=20 \mu \mathrm{m}$, wire diameter $=20 \mu \mathrm{m}$, screen thickness $=42 \pm 1 \mu \mathrm{m}$, material: $1.4401 /$ AISI 316 stainless steel.

\section{REFERENCES}

Hinds, W. C. (1999), Aerosol Technology, Wiley, New York

Kirsch, A. A., Fuchs, N. A. (1968), Studies on Fibrous Aerosol Filters - III. Diffusional Deposition of Aerosols in Fibrous Filters, Ann. Occup. Hyg., Vol. 11, p. 299 - 304

Stein, C., Schröder, F. \& Petzold, A. (2001), The Condensation Particle Size Analyzer: A new instrument for the measurement of ultrafine aerosol size distributions, J. Aerosol Sci., 32, S381 - S382.

Schröder, F. (2000), Vertikalverteilung und Neubildungsprozesse des Aerosols und partikleförmiger Flugzeugemissionen in der freien Troposphäre und Tropopausenregion, Dissertation, LMU München 